DOI: $10.17805 / z p u .2019 .1 .14$

\title{
Феномен постправды: девальвация факта в медийном дискурсе
}

\author{
А. Ю. ГАРБУЗНЯК \\ МОСКОВСКИЙ ГУМАНИТАРНЫЙ УНИВЕРСИТЕТ
}

Статья посвящена теоретическому анализу и концептуализации феномена постправды. В 2016 г. составители Оксфордского словаря выбрали термин «постправда» словом года. В словарь оно вошло как прилагательное со значением «относящийся к или указывающий на обстоятельства, в которых объективные факты менее влиятельны в формировании общественного мнения, чем обращение к эмоциям и личным убеждениям(граждан)». Феномен постправды возникает в рамках избирательного процесса в зарубежных странах (США, Великобритании, Франции) и находит выражение в неожиданном, непредсказуемом итоге выборов. Предпринятые исследования, в том числе социологические, показывают, что мы имеем дело с неким новым механизмом формирования общественного мнения.

У феномена постправды есть как политологический, так и коммуникативный аспект. Политологический аспект связан с так называемым стратегическим голосованием на выборах, когда избиратель руководствуется продуманной стратегией, основанной на его личных убеждениях. Коммуникативный аспект показывает, как эти убеждения формируются. Важную роль в этом процессе играет медийный нарратив, который все меньше отражает реальную политику. Постправда рассматривается как коммуникативный процесс, порождающий нарратив с определенными свойствами: отдельные факты и аналитические выводы обладают в нем меньшей убеждающей силой, чем готовые интерпретации. Эти интерпретации резонируют с личными убеждениями граждан и культивируются, в частности, в политизированных интернет-сообществах.

Ключевые слова: постправда; интерпретация; фейк; медийный нарратив; Дональд Трамп

\section{ВВЕАЕНИЕ}

C овременная политическая среда развивается не менее динамично, чем сфера высоких технологий. Трансформация привычных моделей взаимодействия власти, общества и массмедиа ведет к возникновению новых социально-политических феноменов, нуждающихся в определении и концептуализации.

Один из таких феноменов - «постправда» (Post-truth) - возникает в условиях расширения структуры медиаполитического поля: новые медиа начинают играть все более существенную роль в установлении повестки дня (New media ... , 2010: Электронный ресурс) и обусловливают новое качество медиаэффектов.

Маркировка данного явления происходит в публицистике (ряд материалов СМИ, где появляются первые дефиниции термина «постправда», будет рассмотрен ниже), однако вскоре к его исследованию подключаются социологи и коммуникативисты (Corner, 2017; Modreanu, 2017; Chernenko, 2017): актуальный научный инструментарий оказывается недостаточным для объяснения дисфункциональных эффектов постправды в публичной политике.

В основу статьи «Post-truth» Оксфордского словаря легло определение, вызревшее в СМИ на протяжении 2015-2016 гг. В соответствии с практикой употребления нового термина в англоязычных источниках в словаре он рассматривается в качестве прилагательного со значением «относящийся $\kappa$ или указывающий на обстоятельства, в которых объективные факты менее влиятельны в формировании общественного мнения, чем обращение к эмоциям и личным убеждениям (граждан)» (Word ... , 2016: Электронный ресурс; курсив наш. - А. Г.) 
Аанная словарная дефиниция представляется недостаточной, поскольку указывает на родовые характеристики феномена (воздействие на общественное мнение через эмоции, пренебрежение к фактам, т. е. использование иррациональных методов убеждения), но не отражает его специфики. Есть и другие явления и процессы, обладающие сходными признаками: пропаганда, фрейминг, симулякры, новости-фейки. Аля уточнения этого определения и концептуализации понятия необходимо выявить сущностные особенности феномена постправды и характер порождающих его условий.

\section{ПОСТПРАВАА И ПУБАИЧНАЯ ПОАИТИКА}

Феномен постправды возникает в 2015-2016 гг. в рамках избирательного процесса в зарубежных странах. Аналитики не считают выборы обязательным условием его возникновения, но именно электоральные аномалии последних лет активизировали внимание к явлению постправды. К ним чаще всего относят победу Аональда Трампа на выборах президента США (Boston, 2015: Электронный ресурс), голосование британцев за выход страны из Евросоюза (Goodley, 2017) и победу на выборах президента Франции Эммануэля Макрона - политика, о котором еще год назад никто не слышал (Kılıçkaya, 2017: Электронный ресурс).

Феномен постправды, безусловно, объемнее, чем можно заключить из определения в Оксфордском словаре. Там речь идет лишь о противопоставлении импульсивного политического поведения (под влиянием эмоций) рациональному (через анализ фактов), однако это явление давно исследовано. Специалисты в области анализа электоральных процессов между тем отмечают (Голосов, 2017: Электронный ресурс), что поведение избирателей в упомянутых и некоторых других случаях не вписывается в известные политологии модели. Это значит, что есть основания говорить о серьезных изменениях в отношениях власти и общества, симптомами которых наблюдаемые аномалии являются.

Практическая подитология подходит к объяснению этих изменений через выявление и анализ моделей стратегического голосования на выборах. Под стратегическим голосованием понимается выбор не предпочтительного кандидата (партии), а наиболее приемлемого по определенным соображениям. Здесь важно, что избиратель не руководствуется интересами (профессиональными, экономическими, общественными и др.), не голосует за понравившийся образ, а имеет некоторую стратегию, связанную с его личными убеждениями.

Стратегия может быть связана с вероятностью победы того иди иного кандидата. Например, при мажоритарной избирательной системе избиратель голосует за наиболее приемлемого кандидата из двух сильнейших (Аюверже, 2000: 286), потому что понимает: голос, отданный за предпочтительного, но слабого кандидата, с большой вероятностью пропадет.

Стратегия, основанная на личных убеждениях избирателя, может также компенсировать недостаток его знаний. Наблюдение за электоральным поведением американцев показало, что для оценки политических инициатив они применяют довольно примитивную эвристику (Roberts, 2010: Электронный ресурс). Например, смотрят на то, как инициатива одной партии оценивается другими политическими силами. Межпартийный консенсус при таком подходе будет в общественном мнении очень сильным аргументом в пользу данной инициативы и ее авторов. Своего рода консенсусом будет выглядеть поддержка предложения даже небольшим числом депутатов из оп- 
позиционной партии. В итоге политический перевес оказывается не у той партии, которая предлагает избирателям лучшее решение их проблем, а у той, где жестче внутрипартийная дисциплина и действует принцип: никогда не голосовать за предложения оппонентов.

Стратегическое голосование, как частный случай проявления феномена постправды, показывает, что важным фактором политического процесса становятся личные убеждения граждан, которые далеко не всегда отражают повестку дня СМИ и не всегда фиксируются соцопросами. Ааконичная формула французского социолога П.-И. Шереля «аудитория - эхо СМИ» здесь уже не работает.

Исследование постправды должно как минимум объяснить происхождение этих личных убеждений, как максимум - раскрыть новые механизмы формирования общественного мнения. Поэтому коммуникативный аспект данного феномена заслуживает особого внимания. С ним связана и первая попытка концептуализации термина «постправда ${ }^{1}$. Ее предпринимает в 2010 г. американец А. Робертс, анализируя приведенный выше механизм стратегического голосования в США. «Мы живем в условиях политики постправды: политической культуры, в которой политика (“politics", то есть "общественное мнение и медийный нарратив") стала почти полностью оторвана от политики ("policy" - “сущности законотворчества" или “стратегии развития")» ${ }^{2}$, пишет он в колонке для интернет-издания Grist (Roberts, 2010: Электронный ресурс). Иными словами, Робертс говорит о разрыве между реальным политическим процессом и его символическим отображением - в медийном нарративе и общественном мнении.

\section{СУЩНОСТЬ И ЭФФЕКТ ПОСТПРАВАЫ}

Ключевым для понимания коммуникативной природы постправды является понятие «медийный нарратив», или рассказ о политике средствами массовой информации. Ааже в условиях технологического расширения медийной среды и типов участия граждан в политическом процессе СМИ остаются влиятельным институтом, обеспечивающим коммуникацию общества и власти: они «рассказывают» обществу о власти и власти об обществе. Этот рассказ (нарратив) прямо или опосредованно влияет на политическое поведение граждан и элит.

Соотношение медийного нарратива и личных убеждений граждан - основной вопрос в исследовании коммуникативного аспекта постправды.

Медийный нарратив вкдючает факты и связывающие их интерпретации. Словарное определение постправды говорит об обстоятельствах, в которых факты оказываются менее влиятельны, чем обращение к личным убеждениям граждан.

Таким образом, постправда представляет собой коммуникативный процесс, порождающий нарратив с упомянутыми свойствами: отдельные факты и аналитические выводы обладают в нем меньшей убеждающей силой, чем готовые интерпретации, предлагающие более или менее целостную картину мира, которая резонирует с уже существующими личными убеждениями граждан. Факты, не вписывающиеся в нарратив постправды, отвергаются.

Подобно фейкам, определяемым обычно как «подложный медиапродукт» (Corner, 2017: 1100), постправда оказывается возможна благодаря предвзятости человеческого поведения, ищущего подтверждения существующим верованиям и убеждениям (Combating Fake News ..., 2017: Электронный ресурс). Но в отличие от фейка, который в принципе можно опровергнуть, постправда с трудом поддается опровержению, да- 
же если фейки являются ее инструментом: они прочно встроены в нарратив, обладающий самоценностью.

Наряду с медиаэффектами можно говорить и об эффекте постправды, т. е. о политических последствиях интерпретаций, резистентных к опровергающим их фактам. К таким последствиям можно отнести тот или иной исход выборов.

Электоральный период в целом - наиболее благоприятное время для эмпирических исследований феномена постправды, поскольку итоги голосования представляют собой максимально точный замер политических последствий коммуникации в ходе избирательной кампании.

Не случайно и большинство известных сегодня проявлений феномена постправды связано с выборами. Почему граждане, обладая всей необходимой информацией (или, по крайней мере, имея к ней доступ), голосуют таким образом, как если бы они этой информацией не обладали? В связи с этим вопросом термин «постправда» входит в политический лексикон в 2015-2016 гг., им обусловлена и его этимология: «после того, как правду узнали».

Чаще всего термин применяется для описания коммуникации кандидата в президенты Аональда Трампа со своими избирателями. С самого начала своей избирательной кампании Трамп сделал целый ряд резонансных заявлений, довольно быстро опровергнутых его политическими оппонентами и журналистами с опорой на документально подтвержденные факты, но продолжавших звучать в его публичных выступлениях. "Америка постправды - это Америка, где ложь распространяется политиками и их последователями нагло и открыто почти или абсолютно бессовестно» (Boston, 2015: Электронный ресурс). К такому выводу приходит автор портала TheHumanist.com.

Связка «постправда - Трамп» остается актуальной и в 2016 г., вплоть до самых выборов. «Политикой постправды» в СМИ называется политика неприкрытой лжи, при этом фиксируется доверие избирателей суждениям, которые только «кажутся правдой», но фактически не соответствуют действительности (Freedland, 2016: Электронный ресурс; Art of the lie, 2016: 11). Несмотря на то что эти утверждения были многократно опровергнуты с отсылкой к авторитетным источникам, «версия» Трампа продолжала жить в информационном пространстве и оказывать влияние на настроения избирателей.

Аналогичным образом употреблялся термин post-truth и в связи с массовым распространением дезинформации накануне референдума о выходе Великобритании из Европейского союза, но есть нюанс (Goodley, 2017). Если в случае с Трампом речь идет об откровенной лжи, то здесь имеет место скорее подтасовка фактов, создание интерпретации через отбор «нужных» фактов и игнорирование остальных. Например, сторонники брекзита (brexit, или выхода Великобритании из состава Евросоюза) стремились поразить воображение граждан масштабами затрат: членство в ЕС, заявляли они, обходится Великобритании в 350 млн фунтов стерлингов каждую неделю. При этом не упоминалось, сколько (в денежном эквиваленте) страна получает взамен. «Мы вступили в эпоху политики постправды. Поскольку политика становится более состязательной и в ней доминирует телевизионный перформанс, статус фактов в публичной дискуссии поднимается слишком высоко... Вместо того чтобы безучастно оставаться в стороне от политической схватки, факты сейчас являются одним из главных видов риторического оружия, используемого в ней», - пишет автор «Нью-Йорк таймс» (Davies, 2016: Электронный ресурс). 
«Факты» больше не несут в себе реальность, их теперь массово производят специальные эксперты и агентства, работающие по найму. «Если вы действительно хотите найти эксперта, готового поддержать какой-либо факт, и имеете достаточно денег или политический вес, то вы, скорее всего, сможете это сделать. <...> У людей становится все больше возможностей выстраивать свое потребление информации вокруг собственных мнений и предубеждений, и популистские лидеры их в этом поощряют» (там же).

\section{УСАОВИЯ ВОЗНИКНОВЕНИЯ ПОСТПРАВАЫ}

Внешне постправда имеет много общего с пропагандой, задача которой - «дать информацию в объеме, необходимом для того, чтобы общество приняло решение, запланированное этой пропагандой» (Азялошинский, 2004: 8). Но в отличие от пропаганды постправда существует в условиях многоканального общества при наличии альтернативных источников информации, когда у граждан действительно есть возможность «выстраивать свое потребление информации вокруг собственных мнений» (Davies, 2016: Электронный ресурс). Это своего рода «автопропаганда» внутри небольших сообществ, разделяющих определенные ценности, к которым люди присоединяются в поисках ориентира в море фактов сомнительной достоверности.

Существенно, что постправда возникает в условиях кризиса так называемого объективного факта. Отличить факт от фейка во многих случаях довольно сложно, проверить же достоверность каждого факта невозможно. Случаи разоблачения фото- и видеофейков показывают, что идентифицировать подлог удавалось лишь при наличии существенных «ляпов», когда производством фейка занимались непрофессионалы.

Одним из самых известных примеров было постановочное тушение пожаров в Подмосковье активистами «Молодой гвардии Единой России» Владимиром Бурматовым и Русланом Гаттаровым в 2010 г. На сайтах региональных органов власти не раз находили фотографии с отремонтированными в «Фотошопе» дорогами и другими «решенными» аналогичным образом проблемами.

Инсценировкой падения метеорита рядом с поселком Барыбино в Московской области в июне 2017 г. занимались профессионалы. В результате фейк получился настолько убедительным, что демонстрировался как новость в местных и общероссийских СМИ. Однако через несколько дней жители Барыбино признались, что никакого метеорита не было, а десятки видеороликов в Сети сделало по их заказу пиарагентство. Розыгрыш понадобился для того, чтобы привлечь внимание СМИ к ситуации со строительством в этом районе крупного логистического центра, против которого местные жители протестуют уже третий год.

Войной фото- и видеофактов сопровождается военная операция в Сирии, в которой по разные стороны баррикад участвуют Россия и войска международной коалиции во главе с США. Стороны многократно уличали друг друга в производстве фейков. В каких случаях эти обвинения были справедливы, а в каких нет, даже специалисты не всегда могут дать однозначный ответ. К тому же вопрос ангажированности экспертов стоит не менее остро.

Эти и другие аналогичные инциденты закономерно ведут к обесцениванию факта как такового в представлении некоторой, возможно весьма существенной, части аудитории СМИ. Речь идет прежде всего об активных пользователях социальных сетей, или новых медиа. Специальных исследований о роли новых медиа в возникновении феномена постправды не проводилось, тем не менее есть основания говорить об 
их вкладе в формирование той самой повестки дня, которая, по словам американских публицистов, противоречила «объективным фактам», представленным в СМИ.

О том, что традиционные медиа более не обладают абсолютной монополией на установление повестки дня, свидетельствует ряд исследований последних лет. Их авторы отмечают, что наряду с традиционными СМИ важнейшим фактором формирования и установления повестки дня являются сообщества в социальных сетях (New media ... , 2010: Электронный ресурс). Основная функция новых медиа в этом процессе не производство собственно информации, а аккумулирование по определенным критериям новостей и историй из медийных и немедийных источников (Meraz, 2014: 5). При этом если для традиционного СМИ вопрос источника информации критичен - для журналиста это вопрос профпригодности, - то новые медиа обычно не отличаются большой разборчивостью в выборе источников, здесь куда важнее соответствие факта, фактоида, высказывания или даже фейка позиции сообщества, встраивание его в картину мира, разделяемую его членами. Не беда, если фотография, которую уже в течение нескольких дней «постят» и комментируют десятки тысяч интернет-пользователей, окажется снятой не там и не тогда, - на позицию и мировоззрение членов сообщества это не окажет существенного влияния. В лучшем случае они будут искать более достоверные подтверждения своих идей.

\section{ЗАКАЮЧЕНИЕ}

Аевальвация факта при одновременном росте влияния сетевых сообществ (где позиция, как правило, доминирует над фактом) является базовым условием для возникновения феномена постправды. Аичные убеждения граждан становятся все более опосредованы коммуникацией внутри сообществ единомышленников. Функционирование таких сетевых групп, вероятно, дает ключ к пониманию новых механизмов формирования общественного мнения.

Однако степень влияния новых медиа на общественную повестку дня и на политическое поведение граждан нуждается в дальнейшем, более глубоком исследовании, как и сам феномен постправды. Важно изучить особенности формирования повестки дня в новых медиа, определить роль интерпретаций в распространении новостей-фейков, классифицировать немедийные источники информации, а также продолжить анализ взаимовлияние повесток дня СМИ и социальных сетей.

\section{ПРИМЕЧАНИЯ}

${ }^{1}$ Считается, что термин «post-truth» в значении, близком к сегодняшнему, впервые был использован в 1992 г. в әссе в журнале «The Nation» сербско-американским драматургом Стивом Тесичем в связи с двумя событиями, которые приковывали общественное внимание на тот момент, - скандалом Иран-контрас и войной в Персидском заливе. Затем выходит книга Ральфа Киэса «Эра постправды» (Keyes, 2004), где точного определения понятия пока тоже нет. В обоих случаях слово употребляется в качестве метафоры, публицистического образа.

2 «We live in post-truth politics: a political culture in which politics (public opinion and media narratives) have become almost entirely disconnected from policy (the substance of legislation)».

\section{СПИСОК АИТЕРАТУРЫ}

Голосов, Г. (2017) The Great Debate: Зачем политике наука? [Электронный ресурс] // Полит.Ру. URL: http://polit.ru/article/2017/04/29/golosov (дата обращения: 13.05.2018).

Азялошинский, И. М. (2004) Пропаганда и информация: материалы к обсуждению проблемы // Формула общественного доверия: информация + пропаганда? Специальный выпуск 
бюллетеня «Право знать: история, теория, практика»/ под ред. И. М.Азялошинского. М. : Правозащитный фонд «Комиссия по свободе доступа к информации». 124 с. С. 8-46.

Аюверже, М. (2000) Политические партии. М. : Академический проект. 538 с.

Art of the lie (2016)// The Economist. Sept 10. P. 11.

Boston, R. (2015) Humanists and the Rise of "Post-Truth America" [Электронный ресурс]// The Humanist. December 22. URL: https://thehumanist.com/magazine/january-february-2016/churchstate/humanists-rise-post-truth-america (дата обращения: 15.05.2018).

Chernenko, J. (2017) Political Storytelling in Digital Culture: A Tool for Post-Truth Politics? // Communications. Media. Design. Vol. 2 (1). P. 77-88.

Combating Fake News: An Agenda for Research and Action (2017, conference proceedings) (2017) [Электронный ресурс] // Shorenstein Center, Harvard Kennedy School. URL: https://shorensteincenter.org/combating-fake-news-agenda-for-research (дата обращения: 10.03.2018).

Corner, J. (2017) Fake news, post-truth and media-political change // Media, Culture \& Society. Vol. 39 (7). P. 1100-1107.

Davies, W. (2016) The Age of Post-Truth Politics [Электронный ресурс]// The New York Times. Aug 24. URL: https://www.nytimes.com/2016/08/24/opinion/campaign-stops/the-age-of-posttruth-politics.html (дата обращения: 16.05.2018).

Freedland, J. (2016) Post-truth politicians such as Donald Trump and Boris Johnson are no joke [Электронный ресурс] // The Guardian. May 13. URL: https://www.theguardian.com/commentisfree/2016/may/13/boris-johnson-donald-trump-post-truth-politician (дата обращения: 16.05.2018).

Goodley, S. (2017) Brexit: the price of post-truth pounds in our pockets [Электронный pecyрc]// The Guardian. Feb 12. URL: https://www.theguardian.com/business/2017/feb/12/harold-wilsonpound-in-your-pocket-sterling-inflation (дата обращения: 16.05.2018).

Keyes, R. (2004) The Post-Truth Era: Dishonesty and Deception in Contemporary Life. New York: St. Martin's Press. 320 p.

Kılıçkaya, B. (2017) French Elections: Being an Outsider in a Post-Truth World. [Электронный pecypc]// The New Turkey. April 23. URL: http://thenewturkey.org/french-elections-being-an-outsider-in-a-post-truth-world (дата обращения: 18.05.2018).

Meraz, Sh. (2014) Media Agenda Setting in a Competitive and Hostile Environment: The Role of Sources in Setting Versus Supporting Topical Discussant Agendas in the Tea Party Patriots' Facebook Group // Agenda Setting in a 2.0 World: New Agendas in Communication / ed. by Thomas J. Johnson. New York : Routledge. 289 p. Pp. 1-28.

Modreanu, S. (2017) The Post-Truth Era? // Human and Social Studies. Vol. 6 (3). P. 7-9.

New Media, Old Media: How Blogs and Social Media Agendas Relate and Differ from the Traditional Press (2010) [Электронный ресурс]// Pew Research Center. URL: http://www.journalism. org/2010/05/23/new-media-old-media (дата обращения: 17.03.2018).

Roberts, D. (2010) Post-truth politics [Электронный ресурс]// Grist. April 1. URL: http://grist. org/article/2010-03-30-post-truth-politics (дата обращения: 16.05.2018).

Word of the Year 2016 is... (2016) [Электронный ресурс]// English Oxford Living Dictionaries. URL: https://en.oxforddictionaries.com/word-of-the-year/word-of-the-year-2016 (дата обращения: 17.03.2018).

Аата поступления: 12.12.2018 2.

POST-TRUTH PHENOMENON: THE DEVALUATION OF FACT IN MEDIA DISCOURSE

\section{A. YU. GARBUZNYAK}

MOSCOW UNIVERSITY FOR THE HUMANITIES

The article focuses on the theoretical analysis and conceptualisation of the post-truth phenomenon. In 2016, the term post-truth was chosen word of the year by the Oxford Dictionary compliers. The dictionary defined it as an adjective "relating to or denoting circumstances under which objective 
facts are less influential in shaping public opinion than the appeal to emotion and personal belief (of citizens)". The post-truth phenomenon appears within the framework of the electoral process in western countries (the USA, Great Britain, France) and reveals itself in an unexpected, unpredictable outcome of elections. The undertaken research, including sociological, demonstrates that we are dealing with some new mechanisms of shaping public opinion.

The post-truth phenomenon has both politological and communicative aspects. The politological aspect relates to the so-called strategic voting - when the voter is guided by a thought-out strategy based on their personal beliefs. The communicative aspect reveals how these beliefs are shaped. Media narratives play an important role in this process, reflecting the real policy to a smaller extent. Posttruth is considered as a communicative process generating a narrative that is characterized by special features: separate facts and analytical conclusions are less persuasive than ready-made interpretations. These interpretations resonate with citizens' personal beliefs and are cultivated, in particular, in politically charged Internet communities.

Keywords: post-truth; interpretation; fake; media narrative; Donald Trump

\section{REFERENCES}

Golosov, G. (2017) The Great Debate: Zachem politike nauka? (Lekciya v ramkah obrazovatel'nogo proekta «Grazhdanin Politolog»). Polit.Ru. [online] Available at: http://polit.ru/article/2017/04/29/golosov (access date: 13.05.2018).

Dzyaloshinskij, I. M. (2004) Propaganda i informaciya: materialy $k$ obsuzbdeniyu problemy. Formula obshchestvennogo doveriya: informaciya+propaganda? / ed. by I. M. Dzyaloshinskij. Moscow, Pravozashchitnyj fond «Komissiya po svobode dostupa k informacii». 124 p. Pp. 8-46. (In Russ.).

Dyuverzhe, M. (2000) Politicheskie partii. Moscow, Akademicheskij Proekt. (In Russ.).

Art of the lie (2016) The Economist. Sept 10. P. 11.

Boston, R. (2015) Humanists and the Rise of "Post-Truth America". The Humanist, December 22 [online] Available at: https://thehumanist.com/magazine/january-february-2016/church-state/ humanists-rise-post-truth-america (access date: 15.05.2018).

Chernenko, J. (2017) Political Storytelling in Digital Culture: A Tool for Post-Truth Politics? Communications. Media. Design, vol. 2 (1), pp. 77-88.

Combating Fake News: An Agenda for Research and Action (2017, conference proceedings). Shorenstein Center, Harvard Kennedy School [online] Available at: https://shorensteincenter.org/combating-fake-news-agenda-for-research (access date: 10.03.2018).

Corner, J. (2017) Fake news, post-truth and media-political change. Media, Culture \& Society, vol. 39 (7), pp. 1100-1107.

Davies, W. (2016) The Age of Post-Truth Politics. The New York Times. August 24. [online] Available at: https://www.nytimes.com/2016/08/24/opinion/campaign-stops/the-age-of-post-truth-politics.html (access date: 16.05.2018).

Freedland, J. (2016) Post-truth politicians such as Donald Trump and Boris Johnson are no joke. The Guardian, May 13. [online] Available at: https://www.theguardian. com/commentisfree/ 2016/may/13/ boris-johnson-donald-trump-post-truth-politician (access date: 16.05.2018).

Goodley, S. (2017) Brexit: the price of post-truth pounds in our pockets. The Guardian. February 12. [online] Available at: https://www.theguardian.com/business/2017/feb/12/harold-wilsonpound-in-your-pocket-sterling-inflation (access date: 16.05.2018).

Keyes, R. (2011) The Post-Truth Era: Dishonesty and Deception in Contemporary Life. New York, St. Martin's Press. 196 p.

Kılıçkaya, B. (2017) French Elections: Being an Outsider in a Post-Truth World. The New Turkey, April 23 [online] Available at: http://thenewturkey.org/french-elections-being-an-outsider-in-apost-truth-world (access date: 18.05.2018).

Meraz, Sh. (2014) Media Agenda Setting in a Competitive and Hostile Environment: The Role of Sources in Setting Versus Supporting Topical Discussant Agendas in the Tea Party Patriots' 
Facebook Group. In: Agenda Setting in a 2.0 World: New Agendas in Communication / ed. by Thomas J. Johnson. New York, Routledge. 289 p. Pp. 1-28.

Modreanu, S. (2017) The Post-Truth Era? Human and Social Studies, vol. 6 (3), pp. 7-9.

New Media, Old Media: How Blogs and Social Media Agendas Relate and Differ from the Traditional Press (2010) Pew Research Center [online] Available at: http://www.journalism.org/ 2010/05/23/new-media-old-media (access date: 17.03.2018).

Roberts D. (2010) Post-truth politics. Grist, April 1 [online] Available at: http://grist.org/article/2010-03-30-post-truth-politics (access date: 16.05.2018).

Word of the Year 2016 is... (2016) English Oxford Living Dictionaries [online] Available at: https://en.oxforddictionaries.com/word-of-the-year/word-of-the-year-2016 (access date: 17.03.2018).

Submission date: 12.12 .2018$.

Гарбузняк Алина Юрьевна - кандидат филологических наук, доцент кафедры журналистики Московского гуманитарного университета. Адрес: 111395 , Россия, г. Москва, ул. Юности, А. 5. Тел.: +7 (499) 374-60-91. Эл. адpec: a.garbuznyak@yandex.ru

Garbuznyak Alina Yuryevna, Candidate of Philology, Associate Professor, Department of Journalism, Moscow University for the Humanities. Postal address: 5, Yunosti St., Moscow, Russian Federation, 111395. Tel.: +7 (499) 374-60-91. E-mail: a.garbuznyak@yandex.ru 